\title{
Spindle Cell Carcinoma of the Oral Cavity: A Case Report of a Rare Entity and Review of Literature
}

\author{
${ }^{1}$ Nilima Prakash, ${ }^{2}$ Harish Kumar MS, ${ }^{3}$ Sharada P, ${ }^{4}$ Pradeep GL \\ ${ }^{1}$ Senior Lecturer, Department of Oral and Maxillofacial Pathology, MGV's KBH Dental College and Hospital, Nashik \\ Maharashtra, India \\ ${ }^{2}$ Senior Lecturer, Department of Oral and Maxillofacial Surgery, AECS Maaruti College of Dental Sciences, Bengaluru \\ Karnataka, India \\ ${ }^{3}$ Professor and Head, Department of Oral and Maxillofacial Pathology, AECS Maaruti College of Dental Sciences, Bengaluru \\ Karnataka, India \\ ${ }^{4}$ Senior Lecturer, Department of Oral and Maxillofacial Pathology, MGV's KBH Dental College and Hospital, Nashik \\ Maharashtra, India \\ Correspondence: Nilima Prakash, Senior Lecturer, Department of Oral and Maxillofacial Pathology, MGV's KBH Dental College \\ and Hospital, Panchavati, Nashik-422002, Maharashtra, India, Phone: +919689098897, e-mail: drnilimaprakash@gmail.com
}

\section{Abstract}

Spindle cell carcinoma is a rare and peculiar biphasic malignant neoplasm that occurs mainly in the upper aerodigestive tract. It consists of sarcomatoid proliferation of pleomorphic spindle cells and squamous cell carcinoma. It is considered potentially aggressive in its biological nature with a high incidence of metastases. We report a case of this tumor with an unusual clinical course. The histogenesis of the spindle cell component is discussed in detail in the review of literature.

Keywords: Spindle cell carcinoma, biphasic, histogenesis, immunohistochemistry.

\section{INTRODUCTION}

Spindle cell carcinomas are unusual and distinctive malignant neoplasms of presumed epithelial origin that exhibit prominent spindle cell morphology. Although they are relatively rare, they consistently pose a significant diagnostic challenge to pathologists. ${ }^{1} \mathrm{M}$ any terms including pseudosarcoma (Lane 1957), sarcomatoid carcinoma (K rompecher 1900), collision tumor or carcinosarcoma (Virchow 1864, M inckler et al 1970) have been applied. ${ }^{2}$ This reflects the divergent interpretation of the sarcomatoid component as reactive or neoplastic, mesenchymal or epithelial. ${ }^{3}$ However, the WHO classification of tumors of the oral cavity and oropharynx has placed this disease entity under malignant epithelial tumors of squamous cell carcinoma. ${ }^{2}$ The clinical course is considered aggressive with a high incidence of metastases. ${ }^{4}$

Spindle cell carcinoma is a biphasic tumor composed of surface epithelial changes varying from mild dysplasia to invasive carcinoma in association with, and usually dominated by, an abundant dysplastic-appearing spindle cell-component. ${ }^{5}$ In this article, we describe a case of spindle cell carcinoma involving the mandible with an unusual clinical presentation and review this entity, with special emphasis on the histogenesis.

\section{CASE REPORT}

A 65-year-old female patient presented with a history of fracture of the right side of low er jaw. Patient had undergone extraction of a tooth in that site 10 days back. On examination, fracture of the right angle of mandible was noted. Intraorally, a solitary ulceroproliferative grow th was noted adjacent to the unhealed socket of 47 . The growth was irregular in shape, measuring $2 \times 2.5 \mathrm{~cm}$ in size. Right submandibular lymph nodes were pal pable, tender and fixed. A panoramic radiograph showed the fracture of right angle of mandible and an ill-defined radiolucency associated with unhealed extraction socket of 47 (Fig. 1). An intraoral incisional biopsy was performed. M icroscopic examination of sections revealed haphazard arrangement of few malignant spindle cells. However, since the biopsy tissue was not representative and insufficient to arrive at a definitive diagnosis, the surgeon was advised to rebiopsy the site. On recalling the patient a week after the incisional biopsy, the grow th had increased in size, causing resorption of the affected part of the mandible, sparing only the condylar process. Following the necessary investigations, right hemimandibulectomy was performed under general anesthesia following which she was advised radiation therapy. However, the pati ent was not available for followup and no further treatment was possible. 


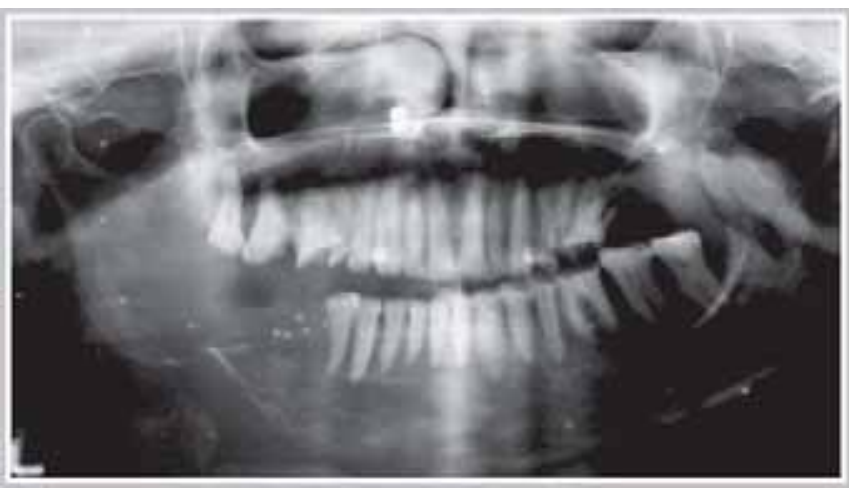

Fig. 1: OPG shows fracture of right angle of the mandible and illdefined radiolucency associated with unhealed extraction socket

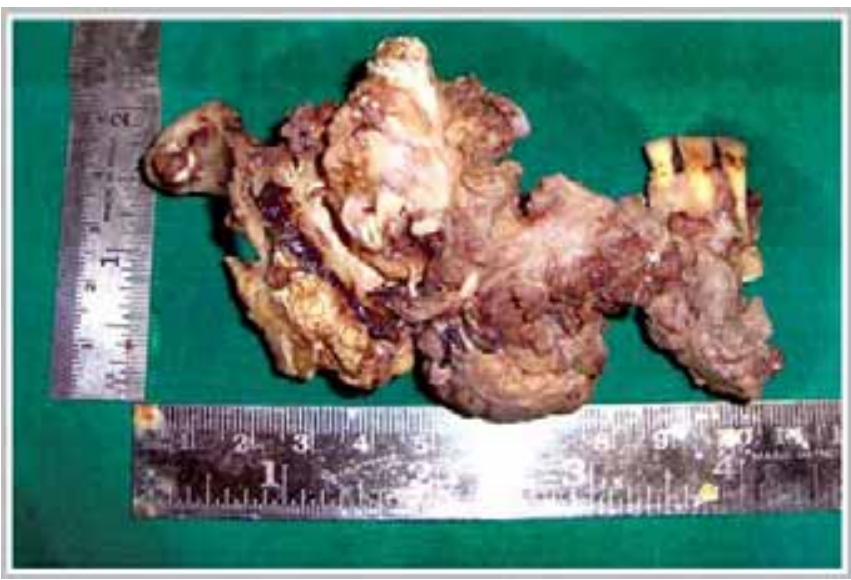

Fig. 2: Hemimandibulectomy specimen: The body of mandible was replaced by a grey white lesion measuring $5.5 \times 3 \times 2.5 \mathrm{~cm}$

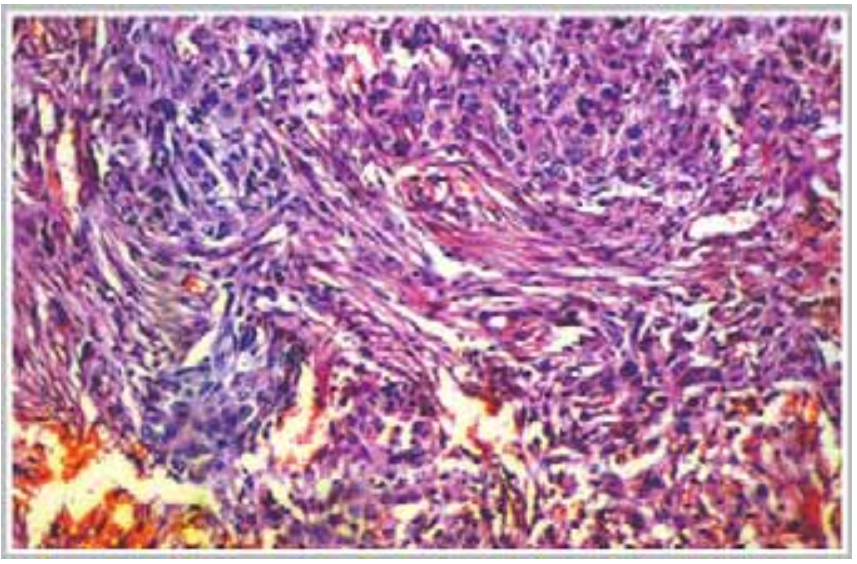

Fig. 3: Malignant epithelial islands (10X)

Grossly, the hemimandibulectomy specimen measured $6 \times 6 \times 3.5 \mathrm{~cm}$. The body of mandible was replaced by a grey white lesion measuring $5.5 \times 3 \times 2.5 \mathrm{~cm}$. The cut surface was grey white in color, firm in consistency (Fig. 2). Histopathologically, the section showed malignant biphasic tumor with islands of carcinomatous cells. The bulk of the tumor was composed of invasive, spindle shaped cells

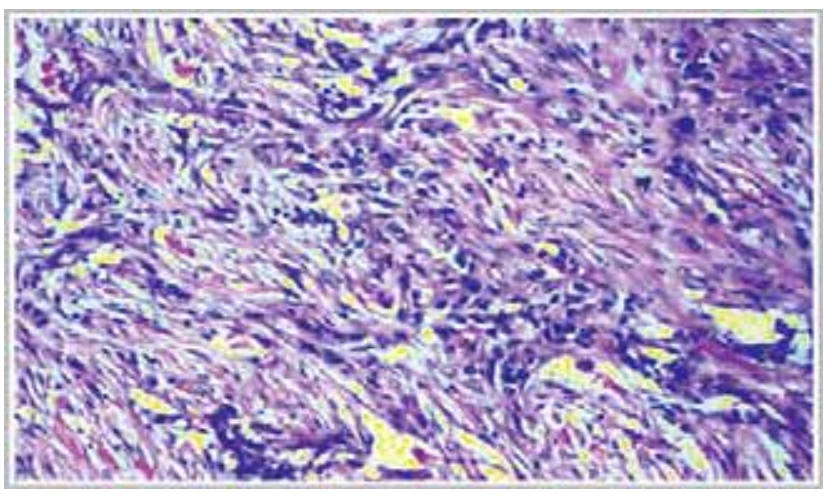

Fig. 4: Malignant spindle cells arranged in storiform pattern (10X)

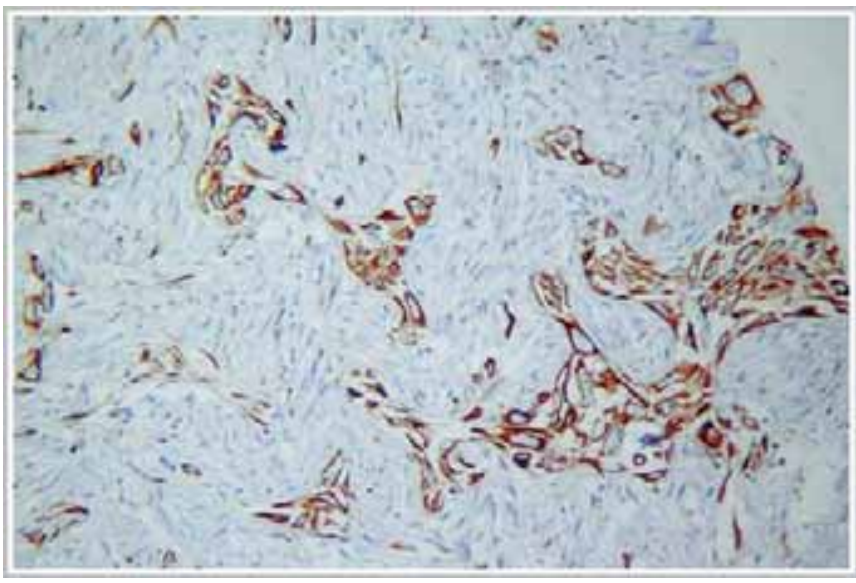

Fig. 5: Spindle cells focally positive for cytokeratin

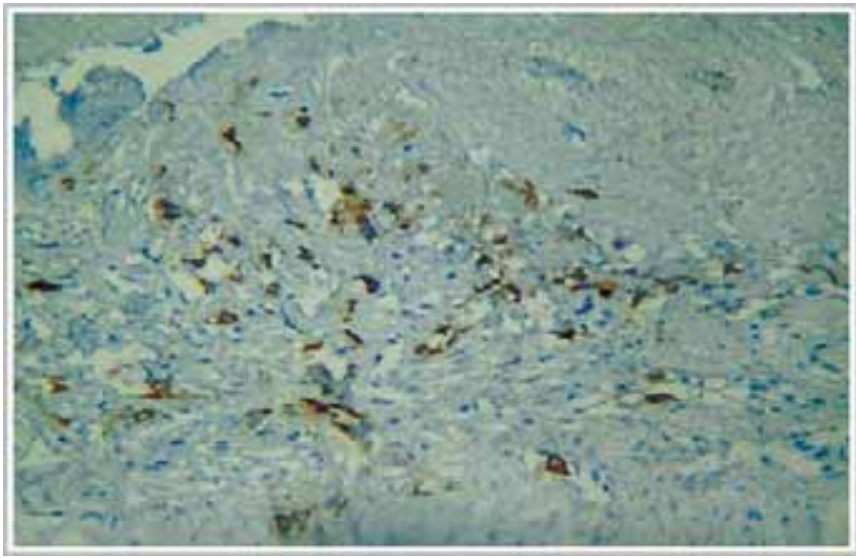

Fig. 6: Spindle cells focally positive for EMA

arranged in storiform pattern (Figs 3 and 4). The tumor showed destruction of the bone with infiltration of the adjacent soft tissue. There was focal infiltration of the submandibular gland. The lesion was diagnosed as spindle cell neoplasm.

To confirm the diagnosis, immunohistochemistry was performed. The epithelial islands were strongly positive for 
Spindle Cell Carcinoma of the Oral Cavity: A Case Report of a Rare Entity and Review of Literature

cytokeratin. The spindle cells were focally positive for cytokeratin and epithelial membrane antigen (Figs 5 and 6).

\section{DISCUSSION}

Spindle cell neoplasms comprise a diverse collection of benign and malignant tumors. A lthough relatively common in other sites in the body, these tumors are uncommon in the oral cavity, reportedly accounting for less than $1 \%$ of all tumors of oral regions. ${ }^{6}$

Spindle cell carcinoma is an unusual form of poorly differentiated squamous cell carcinoma (SCC) consisting of elongated (spindle) epithelial cells that resemble a sarcoma. ${ }^{2}$ Over the years, many terms, including pseudosarcoma, Lane tumor, sarcomatoid carcinoma, carcinosarcoma, pleomorphic carcinoma have been applied to describe this tumor. The term 'spindle cell carcinoma' was first applied by Shervin et al. ${ }^{4}$

A s the plethora of terms may indicate, the histogenesis of spindle cell carcinoma is still controversial. Some authors believe that spindle cell component is a benign stromal reaction against squamous cell carcinoma, while, the others propose that spindle cells are the metaplastic change of malignant squamous cells. ${ }^{7}$ However, the majority of the spindle cell components are non-diploid, which indicates that they are neoplastic and not reactive. ${ }^{5}$ The spindle cells in spindle cell carcinoma are a variant growth pattern of squamous cell carcinoma, neither a non-neoplastic mesenchymal reaction nor a malignant admixture of epithelial and mesenchymal neoplasms. The epithelial and spindle components share a common pathway of tumorigenesis despite their conspicuous divergence at the phenotypic level. ${ }^{8} \mathrm{~K}$ ettle and $\mathrm{K}$ rompecker advanced the concept that carcinoma cells could assume the morphologic characteristics of mesenchymal cells. Following an extensive analysis, Saphir and $V$ ass concluded that most of the lesions were actually carcinomas with spindling features. Stout et al and L ane proposed that the sarcoma-like tissues in these lesions were bizarre but non-neoplastic reactive connective tissue responses to overlying squamous cell carcinomas. ${ }^{3}$ The independent metastasis of 'sarcomatous' elements and a high death rate lend support to the concept of carcinosarcoma. However, other features argue against it. First, areas of transition of basal squamous epithelial cells to spindle forms are commonly observed. Second, lymphatic spread is the most frequent metastatic pathway, the predominant route of carcinomas. Third, the average age at occurrence correlates with that of squamous cell carcinoma of the oral mucosa. Finally, the simultaneous occurrence of epithelial and mesenchymal malignant neoplasms at the same site seems distinctly rare. ${ }^{5}$

The most sensitive and reliable epithelial markers to be used for demonstration of the epithelial phenotype are keratin (AE1/AE3), K1, K18, and epithelial membrane antigen. ${ }^{9} \mathrm{M}$ oreover, double-labeling has indicated keratin and vimentin in individual spindle cells, ${ }^{10}$ thereby illustrating the versatility of the intermediate filament phenotype.

Recently, p63 has been reported as a useful marker for spindle cell carcinoma. ${ }^{11}$ The vimentin positivity reflects that these bizarre fibroblast-like cells are carcinoma cells with true mesenchymal metaplasia. ${ }^{12}$

Ultrastructural analysis by electron microscopy has not resolved the pathogenetic dilemma. Goellner et al suggested that the spindle cell component of these bimorphic tumors consist of non-neoplastic histiocytes and fibroblastic cells. $M$ inckler et al, $\mathrm{M}$ artin et al concluded that the spindle elements were malignant fibroblasts. Leifer et al found that the spindle cells were mesenchymal in appearance but epithelial in origin. Battifora reported the actual transformation of epithelial cells into mesenchymal cells. The presence of junctional complexes between tumor cells, with or without pericellular basal lamina and cytoplasmic skeins of intermediate filaments has been demonstrated. ${ }^{13} \mathrm{M}$ etaplastic alteration of the malignant squamous cell component seems to be supported by histologic and electron microscopic examinations. ${ }^{4}$ Histologic transition from squamous cells to spindle cells has been recognized in some cases. Ultrastructural examinations have al so shown transition from cells with epithelial features to those with increasingly more mesenchymal characteristics. ${ }^{14}$

The spindle shape of the tumor cells has been considered to be caused by the lack of expression of cell adhesion molecules such as cadherins and the consequent alteration of keratin filament network. ${ }^{15}$ Tonofilaments have some effect as intracytoplasmic support struts and assist the cell in resisting deformation from external pressures. The relatively rapid loss of desmosomes and tonofilaments which occur in the cells of spindle squamous tumors render them more susceptible to molding from the surrounding stroma. The cells lying between dense bundles of collagen get squeezed into spindle cells. ${ }^{16}$ It has been suggested that development of the spindle cell phenotype involves 
functional loss of genes that control epithelial differentiation and that conversion to spindle morphology is a recessive entry. ${ }^{4}$ Alonso et al found that spindle cell carcinoma demonstrated prominent local invasiveness and high angiogenic response. It is known that in inflammatory state, epitheloid cell might change in shape into spindle morphology to aid in migration. These facts suggest that the spindle cell pattern might be linked with invasiveness and metastasis. ${ }^{3}$

Clinically, the mean age of occurrence of the lesion is 57 years, with a range of 29 to 93 years. M al es have a slight predilection. The most common presenting findings are swelling, pain and the presence of a nonhealing ulcer. M ost patients are known to have a history of prior radiation therapy. ${ }^{5}$

M icroscopically, spindle cell carcinoma is characterized typically by a biphasic growth pattern, with both squamous and spindle cell components. The squamous component may be represented by dysplasia, carcinoma in situ or frankly invasive carcinoma. The spindle cell component may assume various histological patterns. The most common ones are pleomorphic ( malignant histiocytoma-like) and spindle cell sarcoma (fibrosarcoma-like). However, occasional tumors are less overtly malignant and may be dominated by a resemblance to atypical granulation tissue or fibromatosis. ${ }^{1}$

\section{CONCLUSION}

In conclusion, spindle cell carcinoma in the oral cavity is potentially aggressive and seems to recur easily and to metastasize. Coupled with the problem of histogenesis, there is a range of opinions as to the prognostic factors in this disease. Currently, the most widely accepted theory is that of a neoplastic epithelial cell that can differentiate into both squamous and spindle cell components. Although, it is difficult to predict the biologic behavior in every case, patients whose tumors are deeply invasive tend to have a poor prognosis, whereas those with early-stage tumors usually have an excellent prognosis. If local recurrence occurs, salvage operation should be performed and will be beneficial to patients.

\section{REFERENCES}

1. Jean E Lewis, Kerry D Oslen, Thomas J Sebo. Spindle cell carcinoma of the larynx. Review of 26 cases including DNA content and immunohistochemistry. Human Pathology 1997;28(6):664-73.

2. Sisilia F Fifita, K ayo K uyama, A kira Suzuki, Y oshio Tamaki, Takashi M atsumoto, Hirotsugu $Y$ amamoto. A case of spindle cell carcinoma of the oral cavity: With special reference to cytopathological features and review of literature. Oral Med Pathol 2006;11:127-38.

3. Hsing Hao Su, Sau Tung Chu, Y u Y i Hou, Kuo Ping Chang, Chia J ung Chen. Spindle cell carcinoma of the oral cavity and oropharynx: Factors affecting outcome. J Chin M ed A ssoc 2006;69(10):478-83.

4. M unakata R, Cheng J, Nakajima T, Saku T. Spindle cell carcinoma of the gingiva: Report of an autopsy case. J Oral Pathol Med 1998;27:180-84.

5. Ellis GL, Corio RL. Spindle cell carcinoma of the oral cavity. A clinicopathologic assessment of fifty-nine cases. O ral Surg Oral M ed Oral Path 1980;50(6):523-34.

6. Jordan R CK, Regezi J A. Oral spindle cell neoplasms: A review of 307 cases. Oral Surg Oral M ed Oral Pathol Oral Radiol Endod 2003;95:717-24.

7. R. D oðan K öseoðlu, A ype Sertçelik, Y apar A yva. A rare variant of squamous cell carcinoma of the tongue; spindle cell carcinoma. A nkara Ü niversitesi Týp Fakültesi M ecmuasý 2005;58:11-14.

8. A nsari MA, Hoque M, Califano J, Westra WH. Immunohistochemical p53 expression patterns in sarcomatoid carcinomas of the upper respiratory tract. A m J Surg Pathol 2002;26:1024-31.

9. Thompson L, Wieneke JA, M iettinen $M$, et al. Spindle cell (sarcomatoid) carcinoma of the larynx. A clinicopathologic study of 187 cases. A m J Surg Pathol 2002;26:153-70.

10. Zarbo RJ, Crissman JD, V enkat H, et al. Spindle-cell carcinoma of the upper aerodigestive tract mucosa. A $n$ immunohistologic and ultrastructural study of 18 biphasic tumors and comparison with seven monophasic spindle-cell tumors. A m J Surg Pathol 1986;10:741-43.

11. L ewis J S (J r), Ritter JH, EI-M ofty S. A Iternative epithelial markers in sarcomatoid carcinomas of the head and neck, lung, and bladder- p63, M OC-31, and TTF-1. M od Pathol 2005;18: 1471-81.

12. Gnepp DR. Diagnostic surgical pathology of the head and neck. Saunders: Philadelphia 2009;78-79.

13. Choi HR, Sturgis EM, Rosenthal DI, L una M A, Batsakis JG, El-Naggar AK. Sarcomatoid carcinoma of the head and neck: Molecular evidence for evolution and progression from conventional squamous cell carcinomas. A m J Surg Pathol 2003;27:1216-20.

14. B attifora $\mathrm{H}$. Spindle cell carcinoma: UItrastructural evidence of squamous origin and collagen production by the tumor cells. Cancer 1976;37:2275-82.

15. Guerra MG, Haddow S, B auluz C, et al. Expression of simple epithelial cytokeratins in mouse epidermal keratinocytes harbouring $\mathrm{H}$ arvey ras gene alterations. Cancer Res 1992;52:680-87.

16. Lichtiger B, M ackay B, Tessmer CF. Spindle cell variant of squamous carcinoma-A light and electron microscopic study of 13 cases. Cancer 1970;26(6):1311-20. 